committee's report. In the end, if you don't have a roof over your head, how can you have mental health?" The 2006 federal budget set aside approximately $\$ 800$ million for affordable housing, in cooperation with the provinces.

Dr. Ruth Collins-Nakai, president of the Canadian Medical Association, called the report a "visionary roadmap" and said that Canada's doctors support the recommendations as being "both practical and strategic." - Margot Andresen, Ottawa

DOI:I0.1503/cmaj.060747

\section{Dire warnings redux}

$\mathrm{H}$ ealth Canada is considering new, even more graphic images on tobacco products to reinforce the negative health effects of smoking - a move that is being both lauded and criticized.

Cynthia Callard, executive director of Physicians for a Smoke-Free Canada, says the 16 colour pictures that now grace cigarette packages including images of yellow, rotting teeth, a limp cigarette warning of impotence, a pregnant woman smoking - are powerful, cost-effective tools in the fight against smoking.

Canada led the world in 200r when it launched the 16 coloured pictures on packages coupled with I 6 different warnings inside packages with quitting tips. Brazil and other countries soon followed.

Since then, Canadian smoking rates have declined $2 \%$ (from 5.4 million

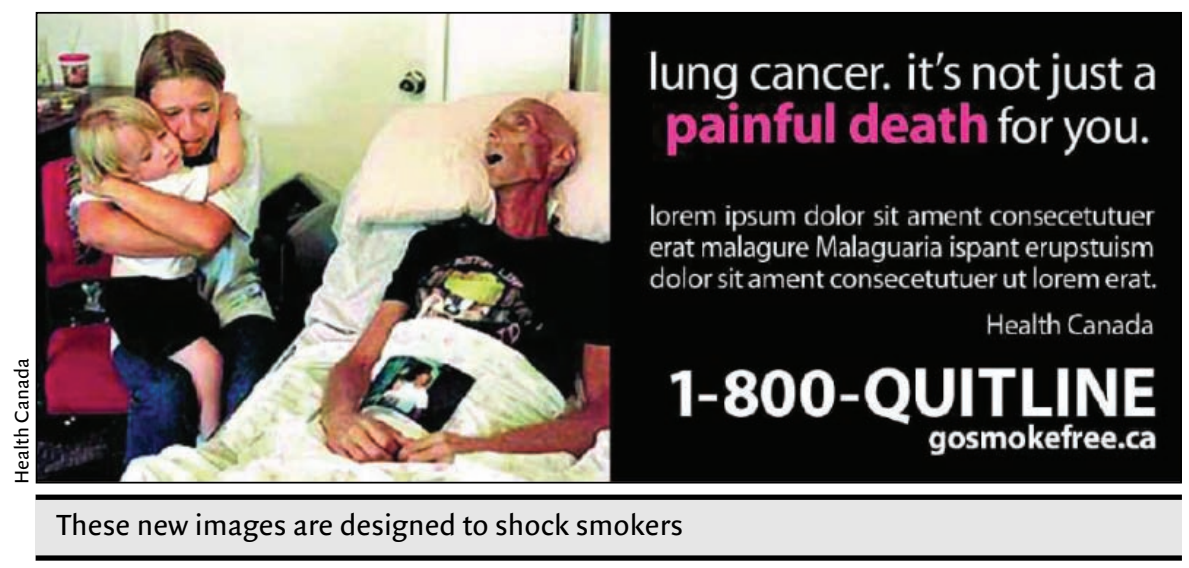

smokers 15 and older in 200 I to just over 5 million during the first half of 2005). Anyone suggesting this is insignificant, says Callard, is missing the complexity of the equation.

Studies have shown that these pictures and the messages, which must cover $50 \%$ of the tobacco package, have registered strongly with smokers and increased motivation to quit, says Callard.

The time has come, however, to replace the now stale images, Callard says.

Evidence from a focus group study conducted by Health Canada last year, and echoed in other studies, indicates that while the old images still get noticed, many smokers now avoid those they dislike (by rejecting certain packages at point of purchase) and rationalizing why the messages don't apply to them (e.g., I'm too young to get sick).

The new images were tested last year on 4 groups of smokers ( 2 in Halifax, 2 in Montréal) i 8 years and older and included photo-shopped images of a pregnant woman and a fetus, both smoking, and a man dying of lung cancer as his wife and daughter sit next to him. A Health Canada spokesperson said the goal was to test basic concepts and reactions. A final decision on new images has not been reached, and new pictures are not expected before late 2007 or 2008.

The Non-Smokers Rights Association, however, is not impressed with Health Canada's new shock ads.

Executive Director Garfield Mahood says the concepts under review focus on individual responsibility instead of the product as the cause of problems. He fears new messages will do little to reduce the 47000 deaths a year caused by smoking.
"We're dealing with an epidemic, and epidemics require dramatic, aggressive, earth-shaking responses from governments," says Mahood. "And this is not what we're seeing with the latest round of warnings." - Pauline Comeau, Ottawa

DOI:I0.1503/cmaj.060723

\section{Full clinical trial disclosure}

\section{needed: expert}

U egislation is required to force pharmaceutical companies to disclose clinical trial information to Canadians, says Dr. Andreas Laupacis of the Canadian Expert Drug Advisory Committee (CEDAC).

Laupacis, who emphasized that he was speaking as an individual, told attendees at a recent Centre for Health Services and Policy Research conference that he is "enormously frustrated" by how long it is taking to bring more transparency to the system.

Pharmaceutical companies don't make complete information about the original trial protocols and outcomes available, he noted. "We see only a few outcome measures from a trial. Are we getting all the information about harm?"

CEDAC is an independent committee of II experts in drug therapy and evaluation who review the effectiveness and cost effectiveness of new prescription drugs. It makes recommendations to Common Drug Review members (including all the provinces and territories except Quebec) about which drugs publicly funded drug plans should list in their formularies, thus making them eligible for reimbursement.

"I lose sleep" over some of CEDAC's recommendations, Laupacis told the conference on national pharmaceutical strategies in February.

One such decision involved whether to list a new, very expensive cancer drug. No good randomized controlled trials had been conducted and the evidence to support the drug was based on some evidence of tumour shrinkage, not on patient outcome, he said. They decided not to list it. 
The decision turned out to be correct, given problems with the drug that later became apparent, but the trend toward extremely expensive drugs has "made it much more emotionally difficult to sit on drug reimbursement committees ... because one knows that no really means no" since most patients could not afford to pay privately for the drugs.

Laupacis also expressed frustration over the trend to shorter duration of most clinical trials, and the "glacial pace of change" in insisting on headto-head trials, in which new versions of drugs are compared to already marketed drugs in the same class, instead of to placebos, so that relative benefit can be determined.

"Increasing openness by everyone is a necessary part of legitimate priority setting," said Laupacis, who is chief executive office of the Institute for Clinical Evaluative Sciences in Toronto. "It is unfathomable to me why we don't insist on the release of all information about clinical trials."

The need to set priorities and to make well-reasoned decisions about approving and funding drugs was underscored at the conference by representatives of the Canadian, British, Australian and New Zealand health care systems, all of whom are struggling to contain rapidly escalating prescription drug costs while ensuring the public's access to useful and safe drugs.

Expenditures on prescription drugs increased by II $_{5} \%$ in British Columbia fromig95/6 to 2004/5; the population grew by only Io\% during this same period, the province's deputy minister of health told the conference. Dr. Penny Ballem added that if current trends continue, health care costs will account for over $70 \%$ of the province's budget by 2017 .

To help in priority setting, Laupacis spoke in favour of including lay members on CEDAC, increasing dialogue with the public about approval and funding of prescription drugs and publishing more "user friendly" documents explaining the committee's recommendations.

Sir Michael Rawlins, chair of the United Kingdom's National Institute for Health and Clinical Excellence, which has a 30-member citizens' council to help with priority setting, echoed the call for more disclosure. "We have to become much more aggressive to have the results of clinical trials available to us," he told attendees at the conference, which was sponsored by the Centre for Health Services and Policy Research at the University of British Columbia.

Laupacis expressed particular concern about having to make listing decisions based on drug trials that have outcomes based on surrogate markers, rather than clinical outcomes in patients. "How are we to interpret surrogate markers? How valid are they?"

Rawlins told the conference that the surrogate marker issue "must be pursued ... we need an international standard."

Laupacis described drug policy in Canada as "a complicated mix of scientific evidence, judgment, altruism, self interest and politics, superimposed on a complex, semi-rational constantly changing overburdened system." Ann Silversides, Toronto

DOI:I0.1503/cmaj.060722

\section{News@ @ glance}

Dementia to double: Over the next 20 years the number of people suffering from dementia is expected to double to 772 0oo, according to Health Canada documents acquired by the Ottawa Citizen. The Alzheimer Society of Canada is urging the government to invest initially at least \$200 million for research and public education. Alzhemier's is the most common type of dementia.

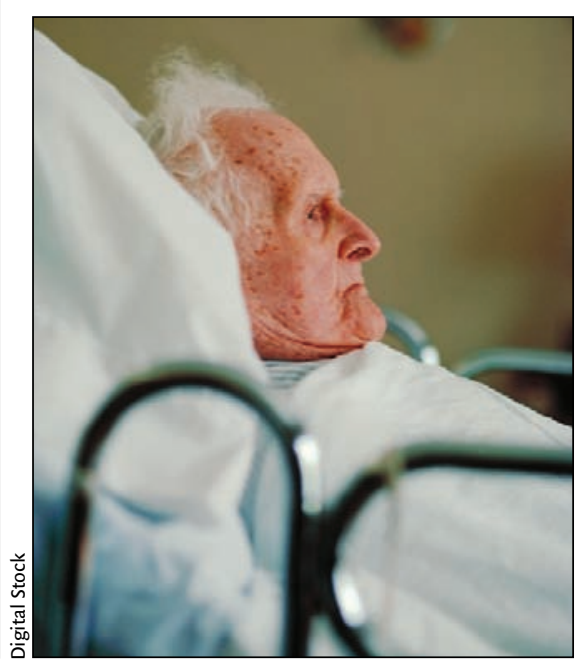

WHO study on FGM: A WHO study of 28393 women in 6 countries finds that those who have had female genital mutilation (FGM) are significantly more likely to have serious complications during childbirth and that their babies are more likely to die as a result of the practice (www.who.int/reproductivehealth/). Those who have been subjected to the most serious form of FGM (FGM III) have on average $30 \%$ more cesarean sections compared to those who have not undergone FGM. Similarly, there is a $70 \%$ increase in the numbers of women who suffer from postpartum hemorrhage. There is also an increased need to resuscitate babies whose mother have undergone FGM (66\% higher in women with FGM III), and the death rate during and immediately after birth is $15 \%$ higher in those with FGM I and 55\% higher in those with FGM III. WHO is working toward eliminating FGM.

High stakes: According to conflict-ofinterest filing with the Federal Ethics Commissioner, Canada's Health Minister Tony Clement holds a $25 \%$ equity position in Prudential Chem Inc., a Toronto firm that makes chemical compounds for the drug industry. To comply with ethics rules, Clement agreed not participate in any discussions or decisions involving the company, or its parent Prudential Consulting Inc. and the affiliated Prudential Business Outsourcing.

Scents ban: The City of Ottawa is going scent-free in all municipal buildings and has launched a public education program. Its citizen's committee on the environment proposed a phased-in citywide ban on scents in all public places, similar to the smoking bylaw that has been in place since 200I. The committee report states that more people are becoming allergic to the chemicals used in scents, and that these have been known to trigger asthma attacks. "People have the right to breathe clean air and not to be exposed to chemical fragrance causing unnecessary health problems," they state. Similar anti-scent campaigns are underway in Nova Scotia. - Compiled by Barbara Sibbald, $C M A J$

DOI:Io.I503/cmaj.060749 